\title{
Germination pretreatments to break hard-seed dormancy in Astragalus cicer L. (Fabaceae)
}

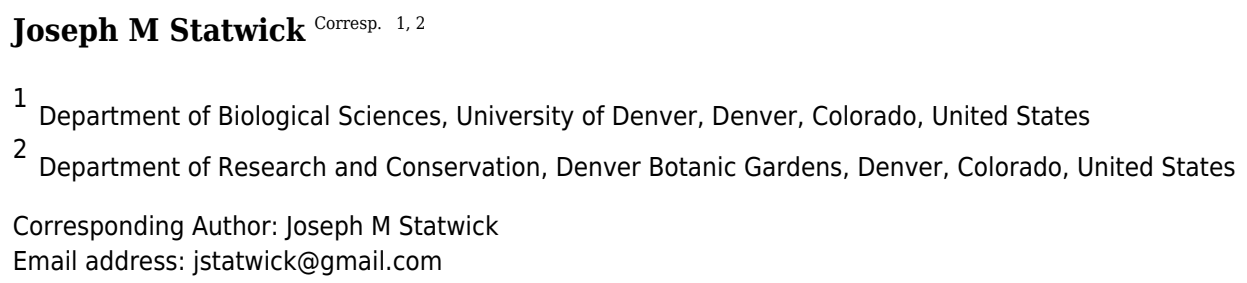

Conservationists often propagate rare species to improve their long-term population viability. However, seed dormancy can make propagation efforts challenging by substantially lowering seed germination. Here I statistically compare several pretreatment options for seeds of Astragalus cicer L.: unscarified controls and scarification via physical damage, hot water, acid, and hydrogen peroxide. Although only $30 \%$ of unscarified seeds germinated, just physical scarification significantly improved germination, whereas one treatment, hot water, resulted in no germination at all. I recommend that rare species of Astragalus, as well as other hard-seeded legumes, be pretreated using physical scarification. Other methods may require considerable optimization, wasting precious time and seeds. 
Germination pretreatments to break hard-seed dormancy in Astragalus cicer L. (Fabaceae)

\author{
Joseph M. Statwick \\ 2345 S Lowell Blvd, Denver, CO 80219 USA \\ jstatwick@gmail.com
}

University of Denver, Department of Biology

Denver, CO 80210, USA

and Denver Botanic Gardens, Department of Research and Conservation

Denver, CO 80206, USA 


\section{ABSTRACT}

1 Conservationists often propagate rare species to improve their long-term population viability.

2 However, seed dormancy can make propagation efforts challenging by substantially lowering

3 seed germination. Here I statistically compare several pretreatment options for seeds of

4 Astragalus cicer L.: unscarified controls and scarification via physical damage, hot water, acid,

5 and hydrogen peroxide. Although only $30 \%$ of unscarified seeds germinated, just physical

6 scarification significantly improved germination, whereas one treatment, hot water, resulted in

7 no germination at all. I recommend that rare species of Astragalus, as well as other hard-seeded

8 legumes, be pretreated using physical scarification. Other methods may require considerable

9 optimization, wasting precious time and seeds. 

rare or threatened populations (Maunder, 1992; Menges, 2008). Such in situ and ex situ propagation techniques are beneficial, so long as these techniques are successful in establishing additional reproductive adults in novel, degraded, or extirpated sites (Maunder, 1992; Menges, 2008). If, however, reintroduction is unsuccessful (which it usually is (Godefroid et al., 2011)), it accomplishes nothing more than wasting resources and even further threatening the species by removing seeds that would have become the future seed bank. At $\sim 3270$ species, Astragalus (Fabaceae) is the largest genus of flowering plants in the world (Watrous and Kane, 2011). Though a few Astragalus are weedy, wide-ranging generalists, specialization on uncommon and infertile soils seems to be a hallmark of the genus (Barneby, 1964). Unfortunately, this specialization appears to restrict many species to small geographic ranges, making them more vulnerable to extinction. In the United States alone, the US Fish and Wildlife service (2014) has listed 5 Astragalus species as threatened and 16 as endangered, with an additional 5 as candidates for listing, and 3 more currently under review. Although the International Union for the Conservation of Nature (IUCN) red list (2014), a global database to track at-risk species, contains less than one half of one percent of known Astragalus species, nearly 40 percent of those with sufficient data are considered "vulnerable" or worse (9

30 vulnerable, 12 endangered, 18 critically endangered, and 1 extinct). NatureServe (2014),

31 meanwhile, lists 100 vulnerable, 58 imperiled, and 31 critically imperiled species, which

32 combine to nearly a third of the 616 Astragalus species in its database. 

different plant families, have hard seed coats and physical dormancy, which often require scarification or stratification to break (Baskin et al., 2008; Long et al., 2012). In particular, low germination rate has been observed for several rare species of Astragalus, including $A$. nitidiflorus (Vicente et al., 2011), A. bibullatus (Albrecht \& Penzagos, 2012), and A. arpilobus (Long et al., 2012). Physical dormancy is generally adaptive; it helps delay seedling emergence until favorable environmental conditions, particularly in habitats with high seasonal or interannual variation (Baskin et al., 2008). Prolonged dormancy of the seed bank may also contribute to the maintenance of genetic diversity in rare Astragalus such as A. albens by resurrecting extirpated genotypes (Neel, 2007). However, this dormancy is counterproductive for ex situ propagation efforts.

literature, including dry heat (Albrecht \& Penzagos, 2012; Chou et al., 2012; Long et al., 2012), wet heat (Acharya et al., 2006, Long et al., 2012), stratification (Acharya et al., 2006; Albrecht \& Penzagos 2012; Long et al., 2012), physical scarification (Miklas et al., 1987, Acharya et al., 2006; Albrecht \& Penzagos, 2012), acid (Miklas et al., 1987, Acharya et al., 2006; Long et al., 2012) smoke water (Chou et al., 2012), etc.

Generally, physical scarification tends to be reliable for Astragalus, but other treatments been successful in some circumstances (Acharya et al., 2006). Long et al. (2012) found that the germination of Astragalus arpilobus by hot water scarification was maximized at $100^{\circ} \mathrm{C}$ for 10 minutes of exposure, yet no amount of time at $90^{\circ} \mathrm{C}$ or below was sufficient to increase germination significantly beyond controls. Fresh Astragalus cicer seeds, meanwhile, had 
56

57

and steam $\left(100^{\circ} \mathrm{C}\right.$ for 5 minutes). Astragalus seeds treated with concentrated sulfuric acid (18M) for 20 minutes have been shown to germinate very successfully (Miklas et al., 1987). Hydrogen peroxide, which is cheaper and safer to use than acid, has been shown to marginally improve the germination of Ribes cereum (Rosaceae) (Rostner et al., 2003), but does not appear to have been tested in the literature for Astagalus.

Despite these successes, it is rare that the results of more than one or two treatments on Astragalus seeds have been compared in the same study. Furthermore, because different species and even collections within species vary in germination rate, (Miklas et al., 1987, Acharya et al., 2006; Albrecht \& Penzagos, 2012), the results of these studies are not directly comparable to one another in order to determine the most effective scarification treatment. I therefore explored five different pre-planting seed treatments to determine which would best promote germination in the generalist forage crop, Astragalus cicer "Oxley".

\section{Methods}

Astragalus cicer L. (cicer milkvetch) is an old-world native that was introduced to North America as a hardy, palatable forage crop (Acharya et al., 2006). "Oxley" is an ecotype that was first collected in the former USSR and introduced to the United States in 1971 (Acharya et al., 2006). Although A. cicer is not rare, it is a suitable model for rare species because it is readily commercially available without threatening wild populations, and because it, like its rare congenerics, is well known for its slow stand establishment, largely due to low germination rates and prolonged seed dormancy (Acharya et al., 2006).

I exposed a total of $250 \mathrm{~A}$. cicer seeds (Granite Seed, Denver, CO) to each of five different scarification treatments $(\mathrm{n}=50)$, starting March 15, 2013 at Denver Botanic Gardens 
79 (DBG) in Denver, Colorado. The scarification treatments were physical damage, hot water,

80 hydrogen peroxide, acid, and a control. Control seeds were planted in $1 \mathrm{~cm}^{2}$ cells in a plastic

81 germination tray, without scarification, on the surface of a seed starter mix, and covered with

82 approximately $3 \mathrm{~mm}$ of vermiculite. Treated seeds were planted in the same manner, after

83 scarification, in the same 288 -cell tray as the control seeds.

84 For the physical scarification treatment, I cut the seed coat opposite the radicle with a pair

85 of infant nail clippers, being careful to not damage the endosperm or embryo. Because my

86 experiment was performed at $\sim 1600 \mathrm{~m}$ altitude where water boils at $<95^{\circ} \mathrm{C}$, I felt the hot water

87 treatment would require a more prolonged soak than is typical. Thus, the seeds were placed in a

88 thermos of boiling water, covered, and soaked for 20 hours before planting. The peroxide treated

89 seeds were soaked in pure ZeroTol, a commercial greenhouse fungicide/algaecide, (BioSafe

90 Systems, East Hartford, CT, 27\% hydrogen peroxide) for one hour before planting, I chose a

91 more concentrated solution for a shorter duration than was effective for Ribes (4-8 hour soak in

$923 \%$ hydrogen peroxide) because of the thicker, more recalcitrant seed coat in legumes and the

93 increasing seed rot observed with longer exposure times (Rostner et al., 2003). Acid treated

94 seeds were soaked in lab grade sulfuric acid $(98 \%, 18 \mathrm{M})$ for five minutes. This is a reduced

95 duration compared to previous studies because at least some seeds were rendered non-viable by

96 acid treatment, although admittedly "very few" (Miklas et al., 1987).

97 All seedlings were reared in a propagation greenhouse at DBG. The total number of seeds

98 germinated in each treatment was recorded approximately twice per week for one month. The

99 potting soil was checked daily and kept evenly moist by DBG horticulture staff. Plants were

100 exposed only to natural sunlight, which, given the date and latitude, ranged between 
101 approximately 12 hours at the beginning of the trial and 13 hours and a half hours at the end of 102 the trial.

103 Germination data were analyzed with a Cox proportional hazards analysis using JMP v10

104 (SAS, Cary, NC, USA). This analysis type is well suited to germination data in that it is intended

105 for time series datasets composed of binary data in which each observation is a replicate (i.e.

106 each seed has germinated or not germinated), and compares observed and expected frequencies

107 with a $\chi$ distribution. It calculates a pairwise risk ratio (RR) between treatments, where a RR

108 greater than one means higher relative germination and a RR less than one means lower relative

109 germination. Alternatively, the RR can be interpreted as the likelihood that a random individual

110 from one treatment will reach the endpoint (i.e. germinate) before a random individual from the

111 other treatment (Spruance et al., 2004). Seeds that did not germinate during the entire treatment

112 period were right-censored, while all other individuals were interval censored. The statistical

113 significance of post-hoc comparisons was assessed at a Bonferroni-corrected alpha of 0.005.

114 Repeated measures ANOVA was not used because calculating the variance of proportions based

115 on grouped binary data is inappropriate in that the proportions are both ordinal and bounded

116 between 0 and 1.

119 Seed treatment was an exceptionally strong predictor of seed germination success

$120\left(\chi^{2}=67.6, \mathrm{P}<0.0001, \mathrm{df}=4, \mathrm{n}=250\right)$. Physically scarified seeds germinated most quickly, and were

121 more than twice as successful as any other treatment (Table 1), with a final germination rate of

$12274 \%$ over 33 days (Figure 1). Statistically similar percentages of unscarified, acid scarified, and

123 peroxide scarified seeds germinated (30\%, 34\%, and 26\%, respectively) (Table 1). No seeds 
124 from the hot water scarification treatment germinated. Across all treatments, the bulk of

125 germination occurred within the first 2 weeks, with virtually no germination after that point 126 (Figure 1).

\section{DISCUSSION}

Although many scarification treatments have been attempted for Astragalus species, my data show that not all treatments are equal in efficacy. In fact, only one treatment, physical scarification, was significantly better than the control, and the hot water treatment was significantly worse than the control, resulting in no germination at all. species use physical scarification as the primary method for breaking seed dormancy. The major disadvantage of using physical scarification, the labor-intensive nature of individually damaging the seed coat with sandpaper, a razor blade, or nail clippers, can be overcome with batch scarification methods. These include abrasive-lined drums or vane polishers for relatively small lots, or commercial seed polishing, hulling, or scarifying equipment for larger lots, albeit at the cost of slightly greater seed loss from damage (Acharya et al., 2006). However, the 10/10 rule of wild seed collection (take no more than $10 \%$ of the seeds from no more than $10 \%$ of the

141 reproductive plants) (Guerrant et al., 2013) severely limits the number of seeds available from

142 rare species, which may have only dozens or hundreds of reproductive individuals within a given

143 year. Because seed numbers from these collections are likely limited to the hundreds, the time

144 required to scarify individually is minimal, whereas the higher seed loss with batch scarification 145 equipment would be unacceptable. If individual scarification is impractical because a species is 146 more common or has been propagated ex situ, I suggest performing additional optimization trials 
147 specific to the type and model of scarification equipment, according to the manufacturer

148 recommendations.

149 Although Astragalus cicer is a relative generalist that would likely not require the sorts of

150 atypical scarification techniques that might be necessary for strongly specialized lineages, to my

151 knowledge, there are no reports of physical scarification being ineffective in Astragalus.

152 Nonetheless, Astragalus as a genus has a very broad range of morphological and physiological

153 variation, with species that are annual or perennial, endemic to mineral or humic soils, etc. Thus,

154 care should be taken in extending these results across the entire range of Astragalus species.

155 Still, whereas other studies have demonstrated that methods involving cold, heat, acid,

156 etc., can improve germination over controls, I recommend against their widespread use in

157 Astragalus, as the studies comparing different durations and intensities (i.e., temperature and

158 concentration) of these treatments have found a relatively narrow range of optimal conditions

159 (Albrecht \& Penzagos, 2012; Chou et al., 2012; Long et al., 2012). Treatments of insufficient

160 duration or intensity appear to be incapable of breaking seed dormancy, whereas treatments of

161 excessive duration or intensity damage not only the seed coat, but the embryo as well, causing a

162 loss of viability (Albrecht \& Penzagos, 2012; Chou et al., 2012; Long et al., 2012). Even when

163 such treatments are better than controls, I have found no reported instance for an Astragalus

164 species in which they are more effective than physical scarification, and they are sometimes still

165 worse (Miklas et al., 1987; Acharya et al., 2006). In addition, some treatments, particularly those

166 that involve concentrated acid, liquid nitrogen, fire, or other reactive substances, could be

167 hazardous and are best avoided unless absolutely necessary.

168 
171 Astragalus species with hard seed dormancy. I advise that, particularly for rare species for which

172 seeds are limited, attempting to optimize other techniques is an unnecessary waste of resources

173 unless physical scarification has been demonstrated to be ineffective.

174

175 Acknowledgements. - I would like to thank Anna A. Sher for her help with data analysis and

176 Jennifer Neale for her comments on the manuscript and facilitation of use of the DBG

177 greenhouse. I also thank the DBG horticulture staff, particularly Mike Bone and Katy Wilcox,

178 for permission to use valuable greenhouse space and planting materials, and for their invaluable

179 aid and expertise. I thank Elizabeth Pilon-Smits for advice on cultivating Astragalus species. 
182 Acharya, S.N., Kastelic, J.P., Beauchemin, K.A. \& Messenger, D.F. (2006) A review of research

183 progress on cicer milkvetch ( Astragalus cicer L .). Can J Plant Sci, 1, 50-62.

184 Albrecht, M.A. \& Penzagos Z, J.C. (2012) Seed germination ecology of three imperiled plants of 185 rock outcrops in the southeastern United States. J Torrey Bot Soc, 139, 86-95.

186 Barneby, R.C. (1964) Atlas of North American Astragalus. The New York Botanical Garden, 187 Bronx, NY.

188 Baskin, J.M., Baskin, C.C. \& Li, X. (2000) Taxonomy, anatomy and evolution of physical 189 dormancy in seeds. Plant Spec Biol, 15, 139-152.

190 Chou, Y.-F., Cox, R.D. \& Wester, D.B. (2012) Smoke Water and Heat Shock Influence

191 Germination of Shortgrass Prairie Species. Rangeland Ecol Manag, 65, 260-267.

192 Guerrant, E.O., Havens, K., Maunder, M., Raven, P.H. \& Conservation, C.P. (2013) Ex Situ

193 Plant Conservation: Supporting Species Survival In The Wild. Island Press.

194 Godefroid, S., Piazza, C., Rossi, G., Buord, S., Stevens, A.-D., Aguraiuja, R., Cowell, C., 195 Weekley, C.W., Vogg, G., Iriondo, J.M., Johnson, I., Dixon, B., Gordon, D., Magnanon, S.,

196 Valentin, B., Bjureke, K., Koopman, R., Vicens, M., Virevaire, M. \& Vanderborght, T. (2011)

197 How successful are plant species reintroductions? Biol Conserv, 144, 672-682. 
198 Long, Y., Tan, D.Y., Baskin, C.C. \& Baskin, J.M. (2012) Seed dormancy and germination

199 characteristics of Astragalus arpilobus (Fabaceae, subfamily Papilionoideae), a central Asian

200 desert annual ephemeral. S Afr J Bot, 83, 68-77.

201 Maunder, M. (1992) Plant reintroduction: an overview. Biodiversity and Conservation, 1, 51-61.

202 Menges, E.S. (2008) Restoration demography and genetics of plants: when is a translocation 203 successful? Aust J Bot, 56, 187.

204 Neel, M. (2008) Patch connectivity and genetic diversity conservation in the federally

205 endangered and narrowly endemic plant species Astragalus albens (Fabaceae). Biol Conserv, $206141,938-955$.

207 Rosner, L S, J T Harrington, D R Dreesen, and L Murray. 2003. "Hydrogen Peroxide Seed 208 Scarification of New Mexico Collections of Ribes Cereum.” Seed Science and Technology $209 \quad 31: 71-81$.

210 Spruance, Spotswood L, Julia E Reid, Michael Grace, and Matthew Samore. 2004. "Hazard 211 Ratio in Clinical Trials." Anitmicrobia Agents and Chemotherapy 48 (8): 2787-2792. 212 doi:10.1128/AAC.48.8.2787.

213 Vicente, M.J., Segura, F., Aguado, M., Migliaro, D., Franco, J. a. \& Martínez-Sánchez, J.J.

214 (2011) Genetic diversity of Astragalus nitidiflorus, a critically endangered endemic of SE Spain, 215 and implications for its conservation. Biochem Syst Ecol, 39, 175-182.

216 Watrous, K.M. \& Cane, J.H. (2011) Breeding Biology of the Threadstalk Milkvetch, Astragalus 217 filipes (Fabaceae), with a Review of the Genus. Am Midl Nat, 165, 225-240. 


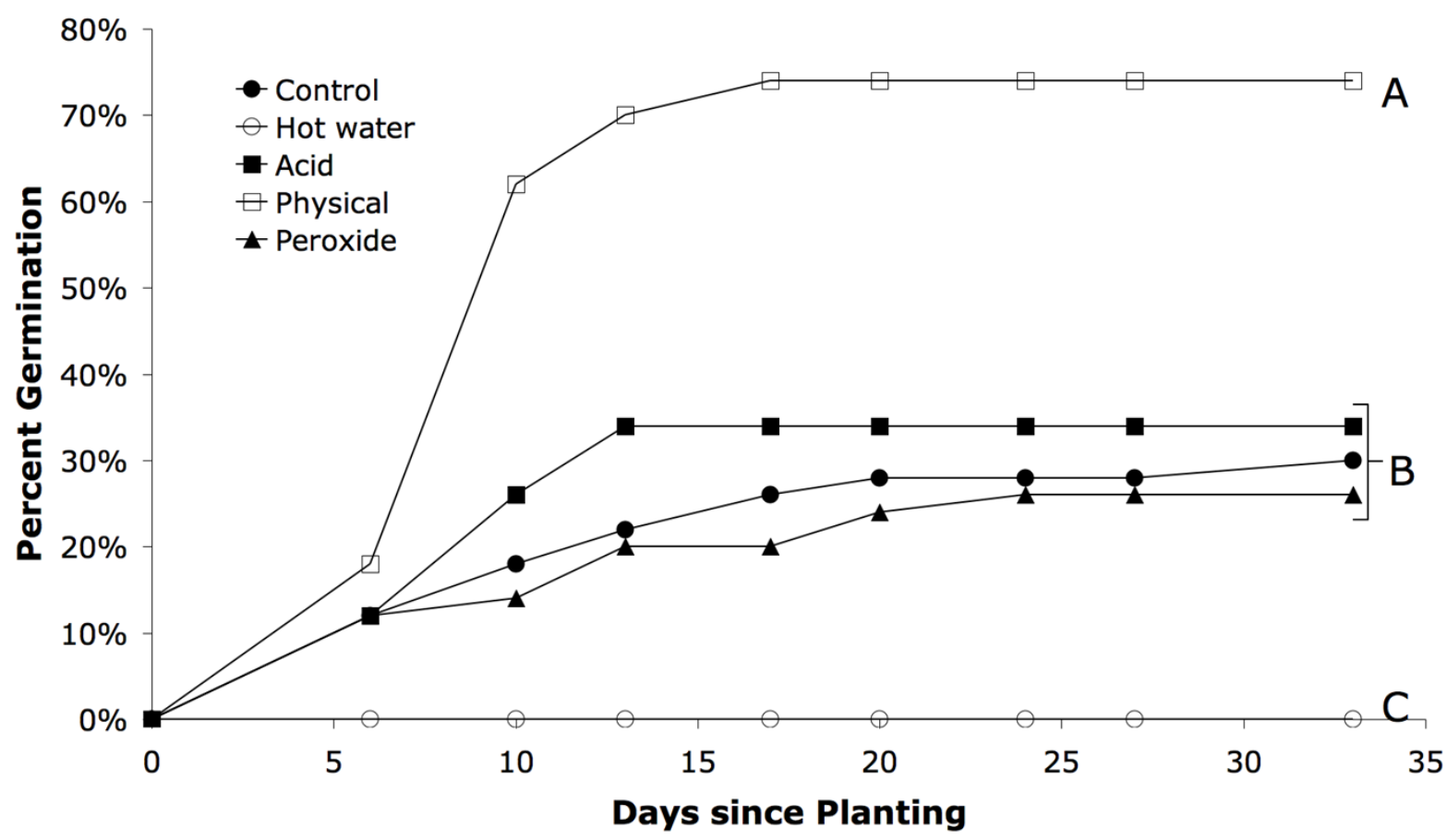

221 Figure 1: Germination rates over time for different scarification treatments for Astragalus cicer..

222 Letters indicate statistically different treatments via proportional hazards analysis. 
224 Table 1: Pairwise risk ratios for treatments, expressed as the ratio of the germination success of

225 the row relative to the column. For example, the risk ratio of controls relative to nail clippers was

2260.32 (32\% as likely to germinate), while the risk ratio of nail clippers relative to controls was

$2273.17\left(317 \%\right.$ more likely to germinate). $\mathrm{n}=50$ for each treatment. Asterisks $\left({ }^{*}\right)$ represent statistical

228 significance at the $\mathrm{P}<0.001$ level. All other post-hoc comparisons were not significant.

\begin{tabular}{|c|c|c|c|c|c|}
\hline Treatments & Control & $\begin{array}{c}\text { Hot } \\
\text { Water }\end{array}$ & $\begin{array}{c}\text { Sulfuric } \\
\text { Acid }\end{array}$ & $\begin{array}{c}\text { Nail } \\
\text { Clippers }\end{array}$ & $\begin{array}{c}\text { Hydrogen } \\
\text { Peroxide }\end{array}$ \\
\hline Control & 1 & $>100^{*}$ & 0.85 & $0.32^{*}$ & 1.17 \\
\hline Hot Water & $<0.01^{*}$ & 1 & $<0.01^{*}$ & $<0.01^{*}$ & $<0.01^{*}$ \\
\hline Sulfuric Acid & 1.17 & $>100^{*}$ & 1 & $0.37^{*}$ & 1.38 \\
\hline Nail Clippers & $3.17^{*}$ & $>100^{*}$ & $2.69^{*}$ & 1 & $3.72^{*}$ \\
\hline Hydrogen Peroxide & 0.85 & $>100^{*}$ & 0.72 & $0.27^{*}$ & 1 \\
\hline
\end{tabular}

